\title{
Physical activity, sedentary behaviors and risk of gestational diabetes mellitus: a population-based cross-sectional study in Tianjin, China
}

\author{
Junhong Leng 1,2, Gongshu Liư', Cuiping Zhang'2, Shijuan Xin ${ }^{3}$, Fang Chen², Baojuan Li², \\ Huiguang Tian'2, Zhijie Yu' ${ }^{4}$, Jaakko Tuomilehto ${ }^{5,6,7,8}$, Gang Hu${ }^{9}$ and Xilin Yang ${ }^{1}$
}

'Department of Epidemiology and Biostatistics, School of Public Health, Tianjin Medical University, Tianjin, China, ${ }^{2}$ Tianjin Women and Children's Health Centre, Tianjin, China, ${ }^{3}$ Tianjin Dong Li Women and Children's Health Centre, Tianjin, China, ${ }^{4}$ Population Cancer Research Program and Department of Pediatrics, Dalhousie University, Halifax, Nova Scotia, Canada, ${ }^{5}$ Centre for Vascular Prevention, Danube-University Krems, Krems, Austria, ${ }^{6}$ Diabetes Prevention Unit, National Institute for Health and Welfare, Helsinki, Finland, ${ }^{7}$ Instituto de Investigacion Sanitaria del Hospital Universario LaPaz (IdiPAZ), Madrid, Spain, ${ }^{8}$ Diabetes Research Group, King Abdulaziz University, Jeddah, Saudi Arabia and ${ }^{9} \mathrm{Chronic}$ Disease Epidemiology Laboratory, Pennington Biomedical Research Center, Baton Rouge, Louisiana, USA

\author{
Correspondence \\ should be addressed \\ to X Yang \\ Email \\ yangxilin@tmu.edu.cn or \\ yxl@hotmail.com
}

\begin{abstract}
Objective: Physical activity in a nonpregnant state or before pregnancy reduces the risk of type 2 diabetes and is also associated with reduced risk of gestational diabetes mellitus (GDM). However, it is uncertain whether physical activity during pregnancy reduces the risk of GDM.

Design and methods: Using an established universal screening system in Tianjin, China, we prospectively recruited 11450 pregnant women within the 12th gestational week from 2010 to 2012. These women underwent a 50-g 1-h glucose challenge test (GCT) at 24-28 weeks of gestation and a 75-g 2-h oral glucose tolerance test if GCT glucose $\geq 7.8 \mathrm{mmol} / \mathrm{L}$. GDM was defined according to the International Association of Diabetes and Pregnancy Study Group's criteria. Self-reported physical activity in the last month was collected at GCT time using a validated questionnaire. Results: GDM developed in $7.3 \%(n=840)$ of the women. Women with GDM were less likely to be engaged in moderate-to-high physical activity during pregnancy than those without $(79.8 \%$ vs $81.6 \%, P=0.191)$. Moderate-tohigh physical activity during pregnancy was associated with decreased risk of GDM (multivariable odds ratio (OR): $0.81,95 \%$ confidence interval $(\mathrm{Cl}): 0.67-0.97)$. Sitting at home for $2-4 \mathrm{~h}$ per day and $>4 \mathrm{~h}$ per day were associated with significantly increased risk of GDM (multivariable OR of sitting time for $2-4 \mathrm{~h}$ vs $<2 \mathrm{~h}: 1.59,95 \% \mathrm{Cl}$ : $1.18-2.15$; OR of sitting time for $>4 \mathrm{~h}$ vs $<2 \mathrm{~h}: 1.73,95 \% \mathrm{Cl}: 1.22-2.43$ ).

Conclusions: Increased physical activity during pregnancy was associated with reduced GDM risk, whereas sedentary lifestyle was associated with increased GDM risk among Chinese pregnant women.
\end{abstract}

\section{Introduction}

The prevalence of gestational diabetes mellitus (GDM) has been increasing worldwide (1), and it comes to be one of the most prevalent metabolic disorders during pregnancy, affecting $16.8 \%$ of all pregnancies (2).
() 2016 European Society of Endocrinology Printed in Great Britain
GDM is not only associated with adverse short-term pregnancy outcomes but also associated with long-term suboptimal health outcomes in both mothers and their offspring $(3,4,5)$. 
Physical inactivity and overnutrition are wellestablished risk factors for diabetes, and lifestyle intervention aiming at increasing physical activity and healthy diet can reduce diabetes risk among highrisk subjects $(6,7,8)$. However, it remains to establish a causal association between physical inactivity and increased risk of GDM. In this connection, a few studies have examined the association between physical activity during pregnancy and GDM risk $(9,10,11,12,13)$, and findings from these studies were inconsistent, possibly due to inadequate study designs, different diagnostic criteria for GDM, shortfall of statistical power, inaccurate measurement of physical activity, and inability to control for confounders. Obesity is a well-recognized risk factor for GDM. Of note, the benefits of physical activity for GDM may be influenced by body composition, although few studies have examined whether the effect of physical activity on GDM risk varies by obesity and/or overweight before pregnancy. Women tend to be less engaged in physical activity and more likely to adopt sedentary behaviors during pregnancy compared with during their nonpregnant period. It is unknown whether reduced sedentary lifestyle and increased physical activity during pregnancy are possible measures for prevention of GDM. Therefore, the current analysis is aimed at examining (i) associations of physical activity and sedentary behaviors, especially sitting time at home during pregnancy, with GDM risk, and (ii) consistency of associations of physical activity and sedentary behaviors during pregnancy with GDM risk by pre-pregnancy obesity and overweight.

\section{Subjects and methods}

\section{Study population and settings}

Tianjin is a municipality directly under the administration of the central government of China. It is situated in the eastern part of the North China, covering an area of $11900 \mathrm{~km}^{2}$ with over 13 million residents. It has six central urban districts, one new urban district, four suburban districts and five counties. There are about 4.3 million residents living in the six central urban districts.

Our group established a universal screening system for GDM in urban Tianjin in 1999 (14). Using this wellestablished screening and management system, we conducted a large population-based prospective study among pregnant women and their offspring in the six central urban districts from 2010 to 2012 with detailed documentation of clinical and biochemical profiles, longitudinally from their first antenatal care visit to the time of screening for GDM in mid-pregnancy and to delivery (15).

From October 2010 to August 2012, 19669 pregnant women attended the primary care hospital for registration of pregnancy and antenatal care within the first 12th gestational week. We sequentially excluded 1080 women who did not perform glucose challenge test (GCT) and 781 women with a positive GCT who did not perform the standard oral glucose tolerance test (OGTT). Of the remaining 17808 women, 11450 who agreed and completed the self-administered questionnaire on physical activity and sedentary behaviors at the time of GCT were included in the current analysis. Ethics approval was obtained from the Ethics Committee for Clinical Research of Tianjin Women and Children's Health Centre (TWCHC), Tianjin, China, and informed consent was obtained from all the women.

\section{Diagnosis of GDM}

A two-step screening procedure was used to identify GDM cases. All pregnant women first underwent a $50 \mathrm{~g}$ 1-h GCT in nonfasting status between 24 and 28 weeks of gestation at primary care hospitals. The women with plasma glucose $(\mathrm{PG}) \geq 7.8 \mathrm{mmol} / \mathrm{L}$ were referred to the GDM clinic within TWCHC where they underwent a $75 \mathrm{~g}$ 2-h OGTT in the morning after at least $8 \mathrm{~h}$ of fasting. PGs at fasting, $1 \mathrm{~h}$ and $2 \mathrm{~h}$ after the glucose load were measured at the Central Laboratory of TWCHC using an automatic analyzer (TBA-120FR, Toshiba, Japan). The inter-assay and intra-assay coefficients of variation for glucose were $<2.59 \%$. GDM was diagnosed according to the International Association of Diabetes and Pregnancy Study Group (IADPSG) cut-points, that is, any of the following PG values is met: fasting PG (FPG) $\geq 5.1 \mathrm{mmol} / \mathrm{L}$, 1 -h PG $\geq 10.0 \mathrm{mmol} / \mathrm{L}$ or $2-\mathrm{h} \mathrm{PG} \geq 8.5 \mathrm{mmol} / \mathrm{L}(16)$.

\section{Assessment of physical activity and sedentary behaviors}

Physical activity and sedentary behaviors in 1 month prior to the GCT time was collected by a self-administered questionnaire. This questionnaire was repeatedly used in our previous studies $(7,17,18)$, and detailed description and validation information are available elsewhere (19). To document physical activity of pregnancy women more accurately, we further included housework physical activity. Briefly, physical activity during pregnancy included occupational, commuting, leisure-time, and housework physical activities. Occupational physical 
activity was divided into three categories: low (work including sitting, e.g., secretary), moderate (work including standing and walking, e.g., store assistant and teacher), and high (work including walking and lifting or heavy manual labor, e.g. farmer and textile workers). Commuting physical activity was divided into three categories according to the type of transportation to and from work, and daily duration of this commuting return journey: using motorized transportation/no walking or cycling ( $0 \mathrm{~min} /$ day), walking or cycling $1-29 \mathrm{~min}$ per day (1-29 min/day), and walking or cycling more than $30 \mathrm{~min}$ per day ( $\geq 30 \mathrm{~min} /$ day). We renamed 'low' when subjects reported $0-29 \mathrm{~min}$ per day, and 'moderate-tohigh' when subjects reported more than 30 min per day. Leisure-time physical activity was classified into two categories: no leisure-time physical activity/engaged in this activity less than $3 \mathrm{~h}$ per week ( $<3 \mathrm{~h} /$ week, low), for example, walking, jogging, swimming, ball games, and engaged in this activity more than $3 \mathrm{~h}$ per week $(\geq 3 \mathrm{~h} /$ week, moderate-to-high). Housework physical activity was classified into three categories: $<1 \mathrm{~h} /$ day (low), $1-2 \mathrm{~h} /$ day (moderate), and $\geq 2 \mathrm{~h} /$ day (high). Physical activities during pregnancy were merged and regrouped into two categories based on the above four types of activities: 'low' when women reported the levels of all four types of activities were 'low' and 'moderate-to-high' when women reported at least one level of the four types of activities was 'moderate-to-high'. In addition to physical activity, we asked how many hours were daily spent on sitting at home, including watching TV, reading, using the computer, and other sitting times at home, including meal time. Sitting time at home was stratified into three categories: $<2,2-4$, and $\geq 4 \mathrm{~h} /$ day.

\section{Other assessments}

Maternal birth date, date of the last menstrual period, family history of diabetes in the first-degree relatives, parity, ethnicity, education attainment, smoking and alcohol consumption before and during pregnancy were collected using questionnaires by care providers or filled out by pregnant women at registration for pregnancy or at the time of GCT.

Nurses at primary care hospitals measured height, weight, and blood pressure (BP) using a standardized protocol. Height was measured without shoes to the nearest $0.5 \mathrm{~cm}$. Weights were measured without shoes and in light clothing to the nearest $0.1 \mathrm{~kg}$ at registration for pregnancy and at the time of GCT respectively. Body mass index (BMI) was calculated as weight in kilogram (kg) divided by squared body height in meter $(\mathrm{m})$ and was categorized as underweight $\left(<18.5 \mathrm{~kg} / \mathrm{m}^{2}\right)$, normal weight $\left(18.5-23.9 \mathrm{~kg} / \mathrm{m}^{2}\right)$, overweight $(24.0-27.9 \mathrm{~kg} /$ $\left.\mathrm{m}^{2}\right)$, and obesity $\left(\geq 28.0 \mathrm{~kg} / \mathrm{m}^{2}\right)$ according to the criteria recommended by the Working Group on Obesity in China (20). Weight at registration for pregnancy was used as pre-pregnancy weight because weight gain in the first trimester of pregnancy is small and negligible (21). Weight gain from pre-pregnancy to GCT was calculated as the difference in weight between at registration for pregnancy and at the GCT. Sitting BP was measured using a calibrated mercury sphygmomanometer after at least 10 min of rest at registration for pregnancy.

\section{Statistical analysis}

Binary logistic regression models were used to obtain odds ratios (ORs) and their 95\% confidence intervals (CIs) of physical activity and sedentary behaviors for GDM risk. A structured adjustment scheme was used to control for confounders. First, we adjusted for maternal age. Secondly, we further adjusted for lifestyle confounders, including habitual smoker and alcohol drinker before or during pregnancy. Thirdly, we further adjusted for other confounders, including height, family history of diabetes in first-degree relatives, parity, education, ethnicity, systolic BP and weight gain from pre-pregnancy to GCT. Fourthly, we further adjusted for pre-pregnancy BMI to check its effect on the association between physical activity, sedentary behaviors, and GDM risk. Ryan-Holm step-down Bonferroni procedure (22) was used to adjust $P$-values and $95 \% \mathrm{CIs}$ where appropriate.

Further subgroup analysis by different pre-pregnancy BMIs was performed to check the consistency of the ORs by obesity/overweight status according to the Chinese criteria (20). The subgroup analysis was repeated by the use of the World Health Organization (WHO)'s criteria, that is, BMI $\geq 25.0 \mathrm{~kg} / \mathrm{m}^{2}$ to define overweight and obesity.

Two sensitivity analyses were also performed. First, we used the 1999 WHO criteria for the diagnosis of GDM (23) to check the consistency across the two sets of criteria. Secondly, we reincluded 455 subjects who had a positive GCT result but were absent from OGTT to check the impacts of exclusion of those subjects. Additional analysis was also performed to compare the distributions of clinical and biochemical characteristics of women included in the final analysis and those excluded.

IBM SPSS Statistics 20.0 (IBM SPSS) was used to perform all the statistical analyses. A $P$-value of less than 0.05 for a two-tailed test was considered to be statistically significant. 


\section{Results}

\section{Characteristics of the study population}

The mean age of 11450 women was 28.5 (s.D.: 2.8) years, $96.9 \%$ were nulliparous, $19.8 \%(n=2263)$ were overweight, and $6.5 \%(n=745)$ were obese. Of them, $81.4 \%$ were engaged in moderate-to-high level of physical activity, and 46.9 and $43.2 \%$ of women were sitting at home for $2-4 \mathrm{~h}$ and $\geq 4 \mathrm{~h}$ per day respectively.

A total of 840 women (7.3\%) developed GDM. Women with GDM were more likely to be engaged in three or more hours of leisure-time physical activity to sit at home for more hours (Table 1). Occupational physical activity, commuting physical activity, and housework physical activity were similar in women with GDM and those without. In addition, women with older age, shorter height, higher pre-pregnancy BMI, higher systolic/ diastolic BP at registration for pregnancy, and lower education level, with family history of diabetes in firstdegree relatives and habitual use of tobacco and alcohol before pregnancy, were more likely to develop GDM.

\section{Physical activity and sedentary behaviors for GDM risk}

In the multivariable analysis models 3 and 4, moderateto-high physical activity during pregnancy was associated with significantly reduced risk of GDM (OR in model 4: 0.81, 95\% CI: 0.67-0.97). In all the four multivariable analysis models, sitting time at home for $2-4 \mathrm{~h}$ per day and more than $4 \mathrm{~h}$ per day significantly increased GDM risks compared with sitting time for less than $2 \mathrm{~h}$ per day in an ordinal manner (ORs and 95\% CIs in model 4: 1.59, $1.18-2.15$ for $2-4 \mathrm{~h} /$ day vs $<2 \mathrm{~h} /$ day; $1.73,1.22-2.43$ for $\geq 4 \mathrm{~h} /$ day vs $<2 \mathrm{~h} /$ day; $P$ for trend: 0.002 ) (Table 2 ). Regardless of physical activity or sitting time at home, the ORs from model 3 to model 4 just changed slightly after further adjusting pre-pregnancy BMI.

\section{Subgroup analysis of physical activity and sedentary behaviors for GDM risk}

The OR of moderate-to-high physical activity for GDM decreased to nonsignificance among women with BMI $<24.0 \mathrm{~kg} / \mathrm{m}^{2}$ but increased among women with BMI $\geq 24.0 \mathrm{~kg} / \mathrm{m}^{2}$ (Table 3). Similarly, the OR of sitting time at home for GDM also numerically decreased among women with BMI $<24.0 \mathrm{~kg} / \mathrm{m}^{2}$ (although still significant) but increased among women with BMI $\geq 24.0 \mathrm{~kg} / \mathrm{m}^{2}$.
The results were similar if the WHO's criteria were used to define overweight and obesity.

\section{Sensitivity analysis}

Using the 1999 WHO's criteria for the definition of GDM $(n=732)$, the protective effects of moderate-to-high physical activity persisted (adjusted ORs: 0.79, 0.65-0.95) (Table 4). Also, the graded direct association between sitting time at home and GDM risk was still significant ( $P$ for trend=0.040). If we assumed that all the 455 subjects who had a positive GCT result but were absent from a standard OGTT did not have GDM, reinclusion of them in the analysis did not change the effect sizes of moderate-to-high physical activity and sitting time at home for GDM. However, if we assumed that all those women had GDM, reinclusion of them in the analysis resulted in attenuated ORs of moderate-to-high physical activity (still significant) and nonsignificant ORs of sitting time at home.

\section{Additional analysis}

There were no statistical differences in most of the measured variables between the women included in the analysis and the women excluded except for maternal age, family history of diabetes, multipara and alcohol drinking habit (Table 5).

\section{Discussion}

Our study found that (i) physical activity during pregnancy was associated with reduced risk of GDM, especially among women who were overweight or obese before pregnancy, and (ii) sedentary behaviors during pregnancy were also associated with the increased risk of GDM, among overweight/obese women as well as among women with normal weight.

Previous studies reported inconsistent findings regarding the association between physical activity during pregnancy and GDM risk (9, 10, 11, 12, 13). A small case-control study of 541 pregnant women found that recreational physical activity during the first 20 weeks of pregnancy was associated with a $48 \%$ decrease in GDM risk (OR: 0.52, 95\% CI: 0.33-0.80) (10). More recently, a meta-analysis of five large studies reported that physical activity in early pregnancy was highly protective against GDM (a pooled OR: 0.76, 95\% CI: 0.70-0.83) (13). More recent RCTs also generated 
Table 1 Clinical and biochemical characteristics of subjects according to the occurrence of gestational diabetes mellitus defined by the IADPSG's criteria. Data are reported in mean \pm s.d. or $n(\%)$.

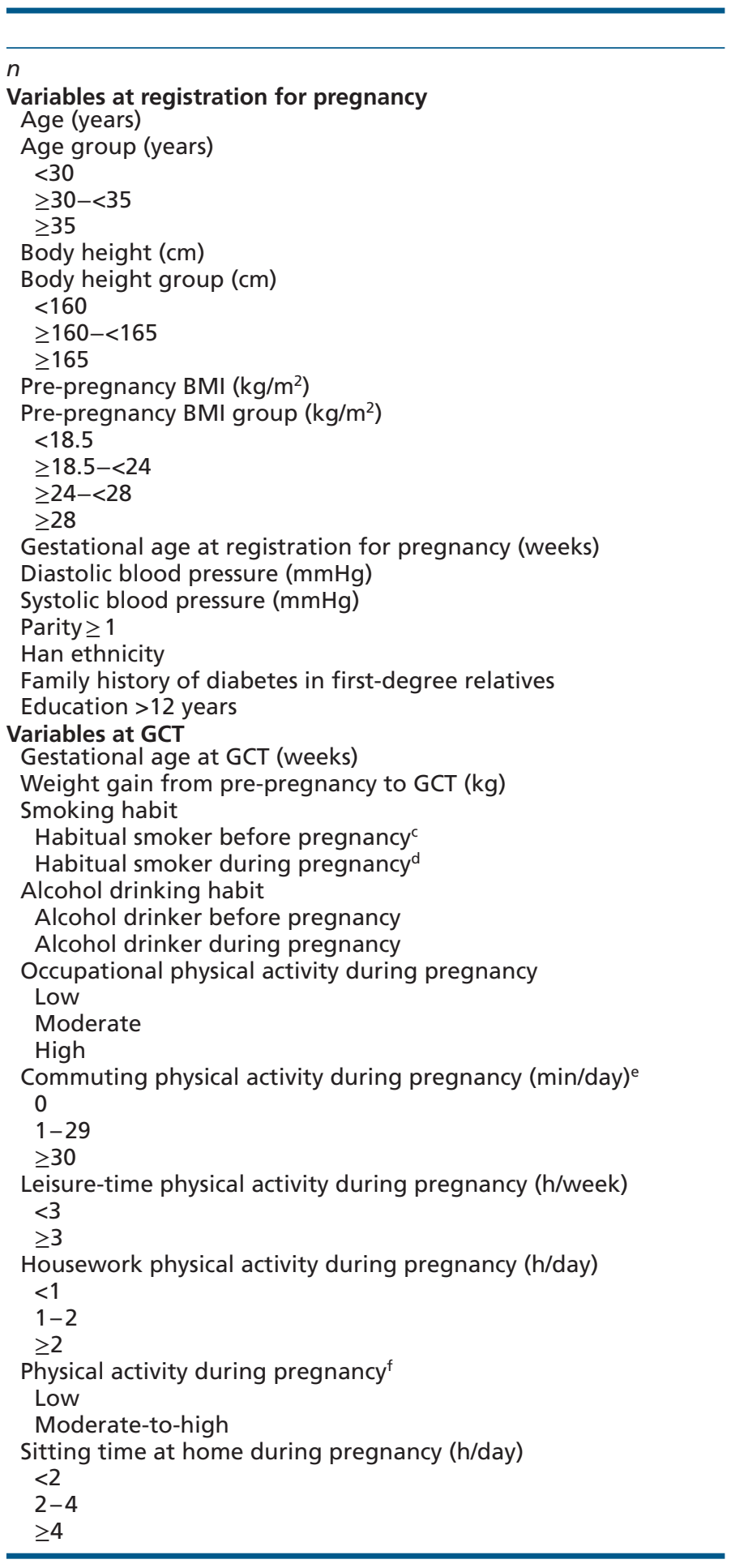

\begin{tabular}{c}
\hline Non-GDM \\
\hline 10610 \\
$28.4 \pm 2.8$ \\
$8130(76.6 \%)$ \\
$2241(21.1 \%)$ \\
$239(2.3 \%)$ \\
$163.2 \pm 4.7$ \\
$1736(16.4 \%)$ \\
$4603(43.4 \%)$ \\
$4269(40.2 \%)$ \\
$22.2 \pm 3.3$ \\
$1073(10.1 \%)$ \\
$6931(65.3 \%)$ \\
$1982(18.7 \%)$ \\
$621(5.9 \%)$ \\
$9.8 \pm 1.6$ \\
$68.3 \pm 7.7$ \\
$105.4 \pm 10.7$ \\
$328(3.1 \%)$ \\
$10128(95.5 \%)$ \\
$847(8.0 \%)$ \\
$8918(84.1 \%)$
\end{tabular}

$$
\begin{array}{r}
24.7 \pm 2.5 \\
7.5 \pm 3.4 \\
319(3.0 \%) \\
71(0.7 \%)
\end{array}
$$

$3356(31.6 \%)$

$99(0.9 \%)$

$9293(87.6 \%)$

$1311(12.4 \%)$

$6(0.1 \%)$

$9794(92.3 \%)$

$250(2.4 \%)$

$566(5.3 \%)$

$9406(88.7 \%)$

$1204(11.3 \%)$

$2528(23.8 \%)$

$6021(56.7 \%)$

$2061(19.4 \%)$

$1954(18.4 \%)$

$8656(81.6 \%)$

$1077(10.2 \%)$

$4979(46.9 \%)$

$4554(42.9 \%)$

$\frac{\text { GDM }}{840}$

P-value

$29.5 \pm 3.2$

$<0.001^{\text {a }}$

$561(66.8 \%)$

$230(27.4 \%)$

$49(5.8 \%)$

$162.8 \pm 4.7$

$0.020^{\mathrm{a}}$

$157(18.7 \%)$

$371(44.2 \%)$

$312(37.1 \%)$

$24.3 \pm 3.9$

$<0.001^{\mathrm{a}}$

$28(3.3 \%)$

$407(48.5 \%)$

$281(33.5 \%)$

$124(14.8 \%)$

$9.9 \pm 1.6$

$70.8 \pm 8.1$

$108.7 \pm 11.3$

$31(3.7 \%)$

$810(96.4 \%)$

$132(15.7 \%)$

$687(81.8 \%)$

\section{$0.104^{\mathrm{b}}$}

$24.8 \pm 1.9$

$7.5 \pm 3.8$

$37(4.4 \%)$

$7(0.8 \%)$

$<0.001^{\mathrm{b}}$

$295(35.1 \%)$

$10(1.2 \%)$

$745(88.7 \%)$

$95(11.3 \%)$

$0(0.0 \%)$

$$
\begin{gathered}
785(93.5 \%) \\
17(2.0 \%) \\
38(4.5 \%)
\end{gathered}
$$

$714(85.0 \%)$

$126(15.0 \%)$

$215(25.6 \%)$

$460(54.8 \%)$

$165(19.6 \%)$

$170(20.2 \%)$

$670(79.8 \%)$

$54(6.4 \%)$

$395(47.0 \%)$

$391(46.5 \%)$

$0.542^{a}$

$<0.001^{\mathrm{a}}$

$<0.001^{\mathrm{a}}$

$0.338^{\mathrm{b}}$

$0.190^{\mathrm{b}}$

$<0.001^{\mathrm{b}}$

$0.082^{\mathrm{b}}$

$0.203^{a}$

$0.766^{\mathrm{a}}$

$0.025^{b}$

$0.578^{b}$

$0.037^{b}$

$0.460^{\mathrm{b}}$

$0.628^{\mathrm{b}}$

$0.485^{b}$

$0.001^{\mathrm{b}}$

$0.454^{b}$

$0.191^{b}$

$0.001^{b}$
BMI, body mass index; GCT, glucose challenge test.

${ }^{a}$ Derived from Student's $t$-test; ${ }^{b}$ Derived from $\chi^{2}$ test or Fisher's exact test; 'Defined as having continuously smoked one or more cigarettes per day for

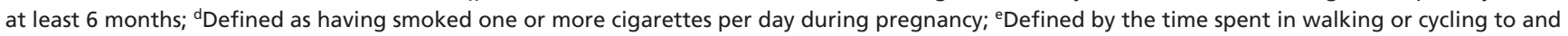
from work; ' Low was defined when subjects simultaneously reported the light level of occupational physical activity, 0-29 min/day of commuting physical activity, $<3 \mathrm{~h} /$ week of leisure-time physical activity, and $<1 \mathrm{~h} /$ day of housework physical activity; and others were defined as 'moderate-to-high'. 
Table 2 The ORs of physical activity and sitting time at home during pregnancy for gestational diabetes mellitus defined by the IADPSG's criteria.

\begin{tabular}{|c|c|c|c|c|}
\hline & $n(\%)$ & OR & $95 \% \mathrm{Cl}$ & P-value \\
\hline \multicolumn{5}{|l|}{ Multivariable analysis $1^{\text {a }}$} \\
\hline \multicolumn{5}{|l|}{ Physical activity during pregnancy } \\
\hline Low & $170(8.0 \%)$ & 1.00 & Reference & \\
\hline Moderate-to-high & $670(7.2 \%)$ & 0.84 & $0.70-1.01$ & 0.057 \\
\hline Sitting time at home during pregnancy (h/day) & & & & $0.001^{f}$ \\
\hline$<2$ & $54(4.8 \%)$ & 1.00 & Reference & \\
\hline $2-4$ & $395(7.4 \%)$ & 1.62 & $1.20-2.17^{e}$ & $0.001^{e}$ \\
\hline$\geq 4$ & $391(7.9 \%)$ & 1.77 & $1.26-2.48^{\mathrm{e}}$ & $<0.001^{\mathrm{e}}$ \\
\hline \multicolumn{5}{|l|}{ Multivariable analysis $2^{\mathrm{b}}$} \\
\hline \multicolumn{5}{|l|}{ Physical activity during pregnancy } \\
\hline Low & $170(8.0 \%)$ & 1.00 & Reference & \\
\hline Moderate-to-high & $670(7.2 \%)$ & 0.84 & $0.70-1.01$ & 0.057 \\
\hline Sitting time at home during pregnancy (h/day) & & & & $0.001^{f}$ \\
\hline$<2$ & $54(4.8 \%)$ & 1.00 & Reference & \\
\hline $2-4$ & $395(7.4 \%)$ & 1.60 & $1.20-2.15^{\mathrm{e}}$ & $0.002^{\mathrm{e}}$ \\
\hline$\geq 4$ & $391(7.9 \%)$ & 1.74 & $1.24-2.44^{\mathrm{e}}$ & $<0.001^{\mathrm{e}}$ \\
\hline \multicolumn{5}{|l|}{ Multivariable analysis $3^{c}$} \\
\hline \multicolumn{5}{|l|}{ Physical activity during pregnancy } \\
\hline Low & $170(8.0 \%)$ & 1.00 & Reference & \\
\hline Moderate-to-high & $670(7.2 \%)$ & 0.83 & $0.69-0.99$ & 0.040 \\
\hline Sitting time at home during pregnancy (h/day) & & & & $0.001^{f}$ \\
\hline$<2$ & $54(4.8 \%)$ & 1.00 & Reference & \\
\hline $2-4$ & $395(7.4 \%)$ & 1.61 & $1.20-2.17^{\mathrm{e}}$ & $0.002^{\mathrm{e}}$ \\
\hline$\geq 4$ & $391(7.9 \%)$ & 1.76 & $1.25-2.48^{e}$ & $<0.001^{\mathrm{e}}$ \\
\hline \multicolumn{5}{|l|}{ Multivariable analysis $4^{d}$} \\
\hline \multicolumn{5}{|l|}{ Physical activity during pregnancy } \\
\hline Low & $170(8.0 \%)$ & 1.00 & Reference & \\
\hline Moderate-to-high & $670(7.2 \%)$ & 0.81 & $0.67-0.97$ & 0.022 \\
\hline Sitting time at home during pregnancy (h/day) & & & & $0.002^{f}$ \\
\hline$<2$ & $54(4.8 \%)$ & 1.00 & Reference & \\
\hline $2-4$ & $395(7.4 \%)$ & 1.59 & $1.18-2.15^{\mathrm{e}}$ & $0.002^{\mathrm{e}}$ \\
\hline$\geq 4$ & $391(7.9 \%)$ & 1.73 & $1.22-2.43^{e}$ & $<0.001^{\mathrm{e}}$ \\
\hline
\end{tabular}

avariables adjusted included maternal age group; ${ }^{b}$ Further adjusted for habitual smokers before or during pregnancy and alcohol drinkers before or during pregnancy in addition to the variables listed in the footnote 'a'; 'Further adjusted for maternal height group, family history of diabetes in first-degree relatives, parity $\geq 1$, education $>12$ years, Han nationality, systolic BP at registration for pregnancy, and weight gain from pre-pregnancy to GCT in addition to the variables listed in the footnote ' $b$ '; ' Further adjusted for pre-pregnancy BMI group in addition to the variables listed in the footnote ' $C$ '; ${ }^{\text {e }}$-values and $95 \% \mathrm{Cls}$ of ORs were adjusted for multiple comparisons by Ryan-Holm step-down Bonferroni procedure; ${ }^{\mathrm{f}} P$ for trend.

conflicting findings. A randomized controlled trial of 855 healthy pregnant women with normal BMI failed to confirm that a 12-week standard exercise program during the second half of pregnancy was able to prevent GDM (12). The LIMIT multicenter, randomized trial found that antenatal dietary and lifestyle interventions, including a combination of dietary, exercise, and behavioral strategies, were unable to reduce the risk of GDM and to improve pregnancy outcomes among overweight or obese women (24). Similarly, another recent multicenter, randomized controlled trial, the UK Pregnancies Better Eating and Activity Trial (UPBEAT) study, reported that a behavioral intervention addressing diet and physical activity in obese pregnant women was also unable to reduce GDM risk (25). However, the Finnish Gestational
Diabetes Prevention Study (26) reported that a moderate individualized lifestyle intervention on diet, physical activity, and weight control could reduce the incidence of GDM by 39\% in high-risk pregnant women with a history of GDM and/or a pre-pregnancy BMI $\geq 30 \mathrm{~kg} / \mathrm{m}^{2}$. Indeed, different study designs and diagnostic criteria for GDM, different definitions of physical activity during pregnancy, and timing of initiation of the intervention may contribute to the inconsistent results. Our findings support the notion that early lifestyle intervention, including physical activity during pregnancy, can reduce the risk of GDM in Chinese pregnant women, although further larger and well-designed RCTs are needed to confirm it. We noticed that women with GDM were more likely to be engaged in three or more hours of leisure-time 
Table 3 Multivariable analysis of ORs of physical activity and sitting time at home during pregnancy for gestational diabetes mellitus defined by the IADPSG's criteria stratified by overweight and obesity status.

\begin{tabular}{|c|c|c|c|c|}
\hline & $n(\%)$ & OR & $95 \% \mathrm{Cl}$ & $P$-value \\
\hline \multicolumn{5}{|l|}{ Among women with BMI $<24 \mathrm{~kg} / \mathrm{m}^{2 a}$} \\
\hline \multicolumn{5}{|l|}{ Physical activity during pregnancy } \\
\hline Low & $87(5.4 \%)$ & 1.00 & Reference & \\
\hline Moderate-to-high & $348(5.1 \%)$ & 0.88 & $0.68-1.12$ & 0.287 \\
\hline Sitting time at home during pregnancy (h/day) & & & & $0.024^{c}$ \\
\hline$<2$ & $30(3.5 \%)$ & 1.00 & Reference & \\
\hline $2-4$ & $200(5.1 \%)$ & 1.49 & $1.01-2.21^{b}$ & $0.048^{b}$ \\
\hline$\geq 4$ & $205(5.7 \%)$ & 1.71 & $1.09-2.69^{b}$ & $0.016^{b}$ \\
\hline \multicolumn{5}{|l|}{ Among women with $\mathrm{BMI} \geq 24 \mathrm{~kg} / \mathrm{m}^{2 \mathrm{a}}$} \\
\hline \multicolumn{5}{|l|}{ Physical activity during pregnancy } \\
\hline Low & $83(16.1 \%)$ & 1.00 & Reference & \\
\hline Moderate-to-high & $322(12.9 \%)$ & 0.75 & $0.57-0.99$ & 0.042 \\
\hline Sitting time at home during pregnancy ( $h /$ day) & & & & $0.040^{c}$ \\
\hline$<2$ & $24(9.0 \%)$ & 1.00 & Reference & \\
\hline $2-4$ & $195(13.7 \%)$ & 1.77 & $1.12-2.79^{b}$ & $0.014^{b}$ \\
\hline$\geq 4$ & $186(14.1 \%)$ & 1.78 & $1.05-3.01^{b}$ & $0.027^{b}$ \\
\hline \multicolumn{5}{|l|}{ Among women with $\mathrm{BMI}<25 \mathrm{~kg} / \mathrm{m}^{2 \mathrm{a}}$} \\
\hline \multicolumn{5}{|l|}{ Physical activity during pregnancy } \\
\hline Low & $104(5.9 \%)$ & 1.00 & Reference & \\
\hline Moderate-to-high & $417(5.5 \%)$ & 0.88 & $0.70-1.10$ & 0.249 \\
\hline Sitting time at home during pregnancy (h/day) & & & & $0.034^{c}$ \\
\hline$<2$ & $37(3.9 \%)$ & 1.00 & Reference & \\
\hline $2-4$ & $244(5.6 \%)$ & 1.47 & $1.03-2.11^{\mathrm{b}}$ & $0.034^{b}$ \\
\hline$\geq 4$ & $240(6.0 \%)$ & 1.61 & $1.07-2.43^{b}$ & $0.019^{b}$ \\
\hline \multicolumn{5}{|l|}{ Among women with $\mathrm{BMI} \geq 25 \mathrm{~kg} / \mathrm{m}^{2 \mathrm{a}}$} \\
\hline \multicolumn{5}{|l|}{ Physical activity during pregnancy } \\
\hline Low & $66(18.3 \%)$ & 1.00 & Reference & \\
\hline Moderate-to-high & $253(14.1 \%)$ & 0.72 & $0.52-0.98$ & 0.034 \\
\hline Sitting time at home during pregnancy (h/day) & & & & $0.027^{c}$ \\
\hline$<2$ & $17(9.0 \%)$ & 1.00 & Reference & \\
\hline $2-4$ & $151(14.8 \%)$ & 1.96 & $1.15-3.37^{b}$ & $0.014^{b}$ \\
\hline$\geq 4$ & $151(15.9 \%)$ & 2.09 & $1.13-3.89^{b}$ & $0.015^{b}$ \\
\hline
\end{tabular}

${ }^{a}$ Variables adjusted in the multivariable analysis are the same as in the multivariable analysis four in Table $2 ;{ }^{b} P$-values and $95 \%$ Cls of ORs were adjusted for multiple comparisons by Ryan-Holm step-down Bonferroni procedure; ${ }^{c} P$ for trend.

physical activity than those without. Although there were no statistical differences in most variables between women with leisure-time physical activity $<3 \mathrm{~h} /$ week and those with leisure-time physical activity $\geq 3 \mathrm{~h}$ /week except for pre-pregnancy BMI and multipara (data was not shown), the women with leisure-time physical activity $\geq 3 \mathrm{~h} /$ week had a higher pre-pregnancy BMI and less likely to be multipara than those with leisure-time physical activity $<3 \mathrm{~h} /$ week. In our analysis, pre-pregnancy BMI but not multipara was associated with GDM. It is possible that higher pre-pregnancy BMI among women with leisuretime physical activity $<3 \mathrm{~h}$ /week might explain part of the inconsistency.

The association between sedentary behaviors during pregnancy and GDM risk has not been well addressed. Although some studies showed a direct association between sedentary behaviors and the risk of type 2 diabetes in nonpregnant population $(27,28)$, to our knowledge, only three studies examined the association between sedentary behaviors and GDM risk $(29,30,31)$. Of them, only one investigated the association of GDM with sedentary behaviors during pregnancy but failed to find any association between television viewing before or during pregnancy and GDM or abnormal glucose tolerance risk (29). In this regard, our study not only reconfirmed that physical activity was associated with a reduced risk of GDM in Chinese pregnant women, but, more importantly, is the first to report that sedentary behaviors in Chinese pregnant women were directly associated with GDM risk after adjusting for other physical activity patterns and confounders.

Both insulin resistance and impaired $\beta$-cell function contribute to the development of GDM. During normal pregnancy, physiological insulin resistance develops to 
Table 4 Sensitivity analysis of multivariable ORs of physical activity and sitting time at home during pregnancy for gestational diabetes mellitus. Sensitivity analysis 2: Reinclusion of the 455 subjects who had a positive GCT result but did not have a standard OGTT and assuming that all the 455 subjects did not have GDM. Sensitivity analysis 3: Reinclusion of the 455 subjects who had a positive GCT result but did not have a standard OGTT and assuming that all the 455 subjects had GDM.

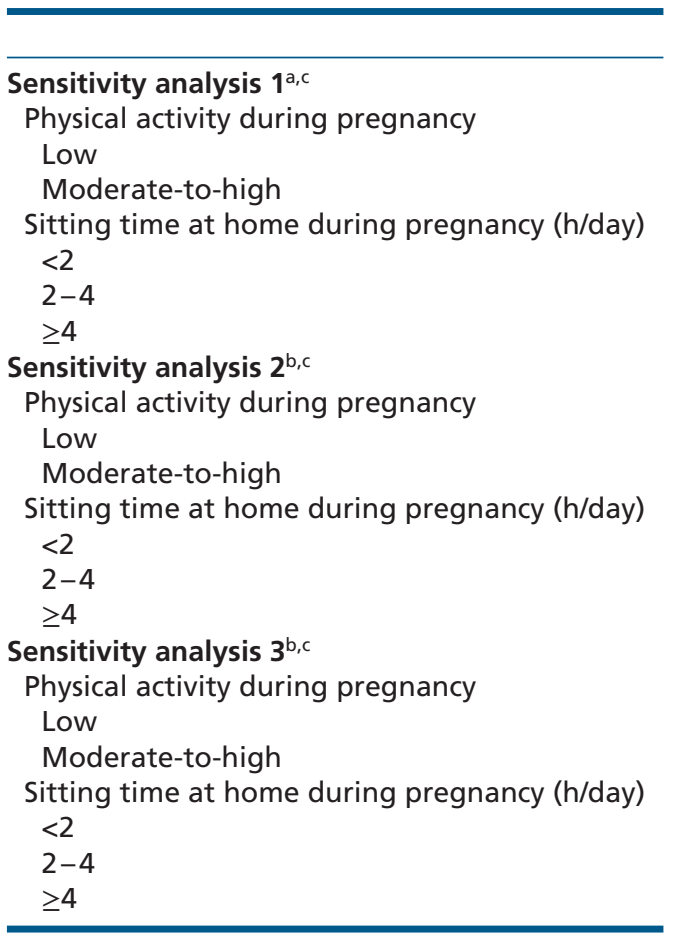

\begin{tabular}{ccc}
\hline $\boldsymbol{n}$ (\%) & & OR \\
\cline { 1 - 1 } $155(7.3 \%)$ & & 1.00 \\
$577(6.2 \%)$ & & 0.79 \\
& & \\
$59(5.2 \%)$ & & 1.00 \\
$327(6.1 \%)$ & & 1.16 \\
$346(7.0 \%)$ & & 1.37 \\
& & \\
$170(7.7 \%)$ & & 1.00 \\
$670(6.9 \%)$ & & 0.81 \\
& & \\
$54(4.5 \%)$ & & 1.00 \\
$395(7.1 \%)$ & & 1.62 \\
$391(7.6 \%)$ & & 1.76 \\
& & \\
$260(11.7 \%)$ & 1.00 \\
$1035(10.7 \%)$ & 0.84 \\
$115(9.6 \%)$ & 1.00 \\
$604(10.8 \%)$ & 1.14 \\
$576(11.2 \%)$ & 1.19 \\
\hline
\end{tabular}

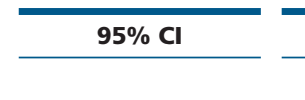

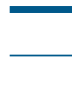

$P$-value

\section{Reference}

$0.65-0.95$

0.014

Reference

$0.87-1.56^{\mathrm{e}}$

$0.98-1.91^{e}$

$0.040^{\mathrm{d}}$

$0.313^{e}$

$0.074^{\mathrm{e}}$

$\begin{array}{lr}\text { Reference } & \\ 0.68-0.98 & 0.026 \\ & 0.001^{\mathrm{d}} \\ \text { Reference } & \\ 1.20-2.18^{\mathrm{e}} & 0.001^{\mathrm{e}} \\ 1.25-2.47^{\mathrm{e}} & <0.001^{\mathrm{e}}\end{array}$

Reference

$0.73-0.98$

0.026

Reference

$0.92-1.41^{\mathrm{e}}$

$0.93-1.53^{\mathrm{e}}$

$0.287^{\mathrm{d}}$

$0.240^{\circ}$

$0.236^{\mathrm{e}}$

$N(\%)$, number of cases (percentage of number at risk).

a GDM was diagnosed according to the 1999 WHO criteria; ${ }^{b}$ GDM was diagnosed according to the IADPSG cut-points; ${ }^{c}$ Variables adjusted in the multivariable analysis are the same as in the multivariable analysis 4 in Table 2; ${ }^{d} P$ for trend; ${ }^{e} P$-values and $95 \%$ Cls of ORs were adjusted for multiple comparisons by Ryan-Holm step-down Bonferroni procedure.

support the demands of fetal growth and development, which begins at mid-pregnancy and continues until delivery. As a result, secretion of insulin by pancreatic $\beta$-cells increases by $2-2.5$ times to compensate for insulin resistance (32). Compared with women with normal glucose tolerance, those with GDM are unable to secrete enough insulin to meet the metabolic stress of insulin resistance. Increased physical activity improves peripheral insulin sensitivity and regulates glucose levels in nonpregnant population and is also associated with reduced first-phase insulin response in late pregnancy (33). Apart from hormones secreted from placenta, recent data suggested that adipose tissue-derived mediators, such as adiponectin, leptin, resistin, tumor necrosis factor-alpha, and oxidative stress, may be involved in the pathogenesis of insulin resistance in $\operatorname{GDM}(34,35)$. Physical activity-induced improvements in glycemic control might be due to increased insulin sensitivity, beneficial changes in adipokines, and reduced oxidative stress and antioxidant effects (36).

The prevalence of GDM is increasing in parallel with rising overweight and obesity in pregnant population.
Maternal pre-pregnancy BMI is considered to play a role in the association between physical activity and GDM risk. Dye et al. used the Central New York Regional Perinatal Data System and reported that physical activity during pregnancy was associated with a $47 \%$ reduction of GDM risk but only among women with BMI $>33.0 \mathrm{~kg} / \mathrm{m}^{2}$ (11). The enhanced protective effect of increased physical activity among overweight and obese women and the attenuated protective effect among women with normal weight revealed in our study are more likely to suggest that pre-pregnancy BMI may play a moderating role between physical activity and GDM risk. Thus, physical activity may be more effective on the prevention of GDM among overweight and obese women because obesity-related insulin resistance may play a more important role than impaired $\beta$-cell function in GDM development among overweight and obese women. By contrast, for underweight and normal weight women, impaired $\beta$-cell function may be dominant in the development of GDM, resulting in an attenuated benefit of physical activity for the prevention of GDM. Nevertheless, our data support the notion that increased sedentary 
Table 5 Clinical and biochemical characteristics of subjects according to inclusion or exclusion criteria in analysis. Data are presented as mean \pm s.d. or $n(\%)$.

\begin{tabular}{l}
\hline$n$ \\
Maternal age (years) \\
Body height $(\mathrm{cm})$ \\
Pre-pregnancy BMI $\left(\mathrm{kg} / \mathrm{m}^{2}\right)$ \\
Gestational age at registration (weeks) \\
Diastolic blood pressure at registration $(\mathrm{mmHg})$ \\
Systolic blood pressure at registration $(\mathrm{mmHg})$ \\
Parity $\geq 1$ \\
Han ethnicity \\
Family history of diabetes in first-degree relatives \\
Education $>12$ years \\
Smoking habit \\
Habitual smoker before pregnancyc \\
Habitual smoker during pregnancy \\
Alcohol drinking habit \\
Alcohol drinker before pregnancy \\
Alcohol drinker during pregnancy
\end{tabular}

\begin{tabular}{c}
\hline Excluded from the analysis \\
\hline 7764 \\
$28.6 \pm 3.0$ \\
$163.1 \pm 4.7$ \\
$22.3 \pm 3.4$ \\
$9.8 \pm 1.6$ \\
$68.5 \pm 7.7$ \\
$105.6 \pm 10.6$ \\
$290(3.7 \%)$ \\
$7418(95.5 \%)$ \\
$603(7.8 \%)$ \\
$6508(84.1 \%)$
\end{tabular}

\begin{tabular}{c}
\hline Included in the analysis \\
\hline 11905 \\
$28.5 \pm 2.8$ \\
$163.2 \pm 4.7$ \\
$22.4 \pm 3.4$ \\
$9.8 \pm 1.6$ \\
$68.5 \pm 7.8$ \\
$105.7 \pm 10.8$ \\
$374(3.1 \%)$ \\
$11377(95.6 \%)$ \\
$1034(8.7 \%)$ \\
$9974(83.8 \%)$
\end{tabular}

\begin{tabular}{c}
$P$-value \\
\hline$<0.001^{\mathrm{a}}$ \\
$0.226^{\mathrm{a}}$ \\
$0.202^{\mathrm{a}}$ \\
$0.157^{\mathrm{a}}$ \\
$0.442^{\mathrm{a}}$ \\
$0.713^{\mathrm{a}}$ \\
$0.024^{\mathrm{b}}$ \\
$0.943^{\mathrm{b}}$ \\
$0.023^{\mathrm{b}}$ \\
$0.558^{\mathrm{b}}$
\end{tabular}

\begin{tabular}{c}
$226(2.9 \%)$ \\
$36(0.5 \%)$ \\
$2243(28.9 \%)$ \\
$23(0.3 \%)$ \\
\hline
\end{tabular}

\begin{tabular}{cc}
$378(3.2 \%)$ & $0.294^{\mathrm{b}}$ \\
$81(0.7 \%)$ & $0.053^{\mathrm{b}}$ \\
$3786(31.8 \%)$ & $<0.001^{\mathrm{b}}$ \\
$119(1.0 \%)$ & $<0.001^{\mathrm{b}}$ \\
\hline
\end{tabular}

BMI, body mass index.

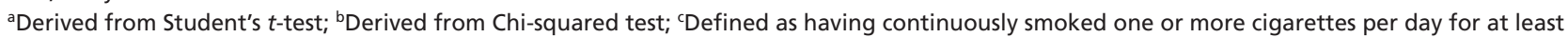
6 months; dDefined as having smoked one or more cigarettes per day during pregnancy.

behaviors during pregnancy increase GDM risk among women with normal pre-pregnancy body weight.

Our study has strengths and limitations. The first strength is that the study was a prospective populationbased study with a large sample size. Secondly, the associations between physical activity and GDM risk were robust because (i) ORs were constant using either the 1999 WHO's criteria or the IADPSG's criteria to define GDM as well as reinclusion of women with incomplete collection of OGTT data, and (ii) nearly all traditional risk factors for GDM were available and the results were significant after adjusting for a variety of confounders. The study had limitations. First, this study was a cross-sectional study, and the findings need to be replicated in other Chinese and non-Chinese populations. If further conformed, randomized controlled trials will be warranted to show that the association between physical activity, sedentary behaviors during pregnancy, and GDM is causal in Chinese and other populations, especially in those whose physical activity levels remain low (37). Secondly, a high proportion of women (42\%) were not included in the analysis due to nonresponse to the physical activity questionnaire or missing other variables. The distributions of clinical and biochemical characteristics were similar in women included and those excluded except for maternal age, family history, multipara, and alcohol drinking (Table 5). Maternal age and family history of diabetes are established risk factors for GDM, and multipara and alcohol drinking are possible risk factors for GDM. In this regard, we had paid special attention to adjustment for all these variables in the multivariable analyses, which might, at least, partially remove the selection bias stemming from the high nonresponding rate. However, the possibility of existence of unmeasured confounders could not be excluded. Thirdly, food habit was not collected in this study. Fourthly, the physical activity questionnaire was old and only validated in nonpregnant populations, but not in pregnant women populations. Also, the physical activity was self-reported and not objectively measured, so the potential self-reporting bias could not be excluded. Fifthly, pre-pregnancy physical activity was not assessed, and its confounding effect could not be removed by statistical analysis. It is possible that part of the benefit of physical activity during pregnancy on the risk of GDM was attributable to good habit of physical activity prior to pregnancy. Sixthly, the IADPSG recommended the use of a one-step OGTT approach to identify GDM, whereas our antenatal care system (also our study) used a two-step procedure to detect GDM in the past 15 years. Some GDM cases may have failed to be identified by the two-step procedure. Consequently, the true effect sizes of physical activity on GDM might be higher than those reported in the study. Seventhly, nullipara accounted for 97\% of our study subjects, and our findings need further replications, especially among multiparous women.

In conclusion, our large population-based study found that high physical activity during pregnancy was significantly associated with reduced GDM 
risk in Chinese pregnant women, especially among pre-pregnancy overweight and obese women. The harmful effect of sedentary lifestyle was not limited to overweight and obese women but extended to women with normal body weight before pregnancy. Given the increasing prevalence of GDM in China and other parts of the world, replications of our findings in other populations of pregnant women are warranted. If further replicated, randomized controlled trials are needed to confirm the benefits of lifestyle interventions for GDM, including increased physical activity and reduced sedentary behaviors.

\section{Declaration of interest}

The authors declare that there is no conflict of interest that could be perceived as prejudicing the impartiality of the research reported.

Funding

This project was supported by BRIDGES (Grant number: LT09-227). BRIDGES is an International Diabetes Federation program supported by an educational grant from Lilly Diabetes.

\section{Author contribution statement}

$X Y, G H$ and $Z Y$ conceived and designed the study. All authors, except $Z Y, J T, G H$, and $X Y$, contributed to the collection of the data. J L analyzed the data and wrote the first draft. All authors gave critical comments and contributed to the writing of the manuscript. $X Y$ (the corresponding authors) and $J \mathrm{~L}$ (the first author) take full responsibility for the work as a whole, including the study design, the access to data, and the decision to submit and publish the manuscript.

\section{Acknowledgments}

The authors thank all doctors, nurses and research staff at 65 primary care hospitals, six district-level women's and children's health centers, and Tianjin Women and Children's Health Center, Tianjin, China, for their participation in this study.

\section{References}

1 Tutino GE, Tam WH, Yang X, Chan JC, Lao TT \& Ma RC. Diabetes and pregnancy: perspectives from Asia. Diabetic Medicine 201431 302-318. (doi:10.1111/dme.12396)

2 International Diabetes Federation. Diabetes Atlas, 6th edn, p 44. Brussels, Belgium: IDF Executive Office, 2013. (available at www.idf. org/diabetesatlas).

3 Kim C, Newton KM \& Knopp RH. Gestational diabetes and the incidence of type 2 diabetes: a systematic review. Diabetes Care 2002 25 1862-1868. (doi:10.2337/diacare.25.10.1862)

4 Metzger BE, Lowe LP, Dyer AR, Trimble ER, Chaovarindr U, Coustan DR, Hadden DR, McCance DR, Hod M, McIntyre HD et al. Hyperglycemia and adverse pregnancy outcomes. New England Journal of Medicine 2008358 1991-2002. (doi:10.1056/NEJMoa0707943)

5 Silverman BL, Metzger BE, Cho NH \& Loeb CA. Impaired glucose tolerance in adolescent offspring of diabetic mothers. Relationship to fetal hyperinsulinism. Diabetes Care 199518 611-617. (doi:10.2337/ diacare.18.5.611)
6 Colberg SR, Sigal RJ, Fernhall B, Regensteiner JG, Blissmer BJ, Rubin RR, Chasan-Taber L, Albright AL \& Braun B. Exercise and type 2 diabetes: the American College of Sports Medicine and the American Diabetes Association: joint position statement executive summary. Diabetes Care 201033 2692-2696. (doi:10.2337/dc10-1548)

7 Hu G, Lindstrom J, Valle TT, Eriksson JG, Jousilahti P, Silventoinen K, Qiao Q \& Tuomilehto J. Physical activity, body mass index, and risk of type 2 diabetes in patients with normal or impaired glucose regulation. Archives of Internal Medicine 2004164 892-896. (doi:10.1001/archinte.164.8.892)

8 Jeon CY, Lokken RP, Hu FB \& van Dam RM. Physical activity of moderate intensity and risk of type 2 diabetes: a systematic review. Diabetes Care 200730 744-752. (doi:10.2337/dc06-1842)

9 Callaway LK, Colditz PB, Byrne NM, Lingwood BE, Rowlands IJ, Foxcroft K \& McIntyre HD. Prevention of gestational diabetes: feasibility issues for an exercise intervention in obese pregnant women. Diabetes Care 201033 1457-1459. (doi:10.2337/dc09-2336)

10 Dempsey JC, Butler CL, Sorensen TK, Lee IM, Thompson ML, Miller RS, Frederick IO \& Williams MA. A case-control study of maternal recreational physical activity and risk of gestational diabetes mellitus. Diabetes Research and Clinical Practice 200466 203-215. (doi:10.1016/j.diabres.2004.03.010)

11 Dye TD, Knox KL, Artal R, Aubry RH \& Wojtowycz MA. Physical activity, obesity, and diabetes in pregnancy. American Journal of Epidemiology 1997 146 961-965. (doi:10.1093/oxfordjournals.aje.a009223)

12 Stafne SN, Salvesen KA, Romundstad PR, Eggebo TM, Carlsen SM \& Morkved S. Regular exercise during pregnancy to prevent gestational diabetes: a randomized controlled trial. Obstetrics \& Gynecology 2012 119 29-36. (doi:10.1097/AOG.0b013e3182393f86)

13 Tobias DK, Zhang C, van Dam RM, Bowers K \& Hu FB. Physical activity before and during pregnancy and risk of gestational diabetes mellitus: a meta-analysis. Diabetes Care 201134 223-229. (doi:10.2337/dc10-1368)

14 Yang X, Hsu-Hage B, Zhang H, Yu L, Dong L, Li J, Shao P \& Zhang C. Gestational diabetes mellitus in women of single gravidity in Tianjin City, China. Diabetes Care 200225 847-851. (doi:10.2337/ diacare.25.5.847)

15 Leng J, Shao P, Zhang C, Tian H, Zhang F, Zhang S, Dong L, Li L, Yu Z, Chan JC et al. Prevalence of gestational diabetes mellitus and its risk factors in Chinese pregnant women: a prospective population-based study in Tianjin, China. PLoS ONE 201510 e0121029. (doi:10.1371/ journal.pone.0121029)

16 Metzger BE, Gabbe SG, Persson B, Buchanan TA, Catalano PA, Damm P, Dyer AR, Leiva A, Hod M, Kitzmiler JL et al. International association of diabetes and pregnancy study groups recommendations on the diagnosis and classification of hyperglycemia in pregnancy. Diabetes Care 201033 676-682. (doi:10.2337/dc09-1848)

17 Hu G, Jousilahti P, Antikainen R, Katzmarzyk PT \& Tuomilehto J. Joint effects of physical activity, body mass index, waist circumference, and waist-to-hip ratio on the risk of heart failure. Circulation 2010121 237-244. (doi:10.1161/CIRCULATIONAHA.109.887893)

$18 \mathrm{Hu}$ G, Qiao Q, Silventoinen K, Eriksson JG, Jousilahti P, Lindstrom J, Valle TT, Nissinen A \& Tuomilehto J. Occupational commuting, and leisure-time physical activity in relation to risk for Type 2 diabetes in middle-aged Finnish men and women. Diabetologia 200346 322-329.

19 Sallis JF, Haskell WL, Wood PD, Fortmann SP, Rogers T, Blair SN \& Paffenbarger RS Jr. Physical activity assessment methodology in the Five-City Project. American Journal of Epidemiology 1985121 91-106.

20 Chen C \& Lu FC. The guidelines for prevention and control of overweight and obesity in Chinese adults. Biomedical and Environmental Sciences 200417 (Supplement) 1-36.

21 Fattah C, Farah N, Barry SC, O'Connor N, Stuart B \& Turner MJ. Maternal weight and body composition in the first trimester of pregnancy. Acta Obstetricia et Gynecologica Scandinavica 201089 952-955. (doi:10.3109/00016341003801706) 
22 Ludbrook J. Multiple inferences using confidence intervals. Clinical and Experimental Pharmacology and Physiology 200027 212-215. (doi:10.1046/j.1440-1681.2000.03223.x)

23 Alberti KG \& Zimmet PZ. Definition, diagnosis and classification of diabetes mellitus and its complications. Part 1: diagnosis and classification of diabetes mellitus provisional report of a WHO consultation. Diabetic Medicine 199815 539-553.

24 Dodd JM, Turnbull D, McPhee AJ, Deussen AR, Grivell RM, Yelland LN, Crowther CA, Wittert G, Owens JA \& Robinson JS. Antenatal lifestyle advice for women who are overweight or obese: LIMIT randomised trial. BMJ 2014348 g1285. (doi:10.1136/bmj. g1285)

25 Poston L, Bell R, Croker H, Flynn AC, Godfrey KM, Goff L, Hayes L, Khazaezadeh N, Nelson SM, Oteng-Ntim E et al. Effect of a behavioural intervention in obese pregnant women (the UPBEAT study): a multicentre, randomised controlled trial. Lancet Diabetes \& Endocrinology 20153 767-777. (doi:10.1016/S22138587(15)00227-2)

26 Koivusalo SB, Rono K, Klemetti MM, Roine RP, Lindstrom J, Erkkola M, Kaaja RJ, Poyhonen-Alho M, Tiitinen A, Huvinen E et al. Gestational diabetes mellitus can be prevented by lifestyle intervention: The Finnish Gestational Diabetes Prevention Study (RADIEL): a randomized controlled trial. Diabetes Care 201639 24-30. (doi:10.2337/dc15-0511)

$27 \mathrm{Hu}$ FB. Sedentary lifestyle and risk of obesity and type 2 diabetes. Lipids 200338 103-108. (doi:10.1007/s11745-003-1038-4)

$28 \mathrm{Hu}$ FB, Leitzmann MF, Stampfer MJ, Colditz GA, Willett WC \& Rimm EB. Physical activity and television watching in relation to risk for type 2 diabetes mellitus in men. Archives of Internal Medicine 2001161 1542-1548. (doi:10.1001/archinte.161.12.1542)

29 Oken E, Ning Y, Rifas-Shiman SL, Radesky JS, Rich-Edwards JW \& Gillman MW. Associations of physical activity and inactivity before and during pregnancy with glucose tolerance. Obstetrics \& Gynecology 2006108 1200-1207.
30 van der Ploeg HP, van Poppel MN, Chey T, Bauman AE \& Brown WJ. The role of pre-pregnancy physical activity and sedentary behaviour in the development of gestational diabetes mellitus. Journal of Science and Medicine in Sport 201114 149-152. (doi:10.1016/j.jsams.2010.09.002)

31 Zhang C, Solomon CG, Manson JE \& Hu FB. A prospective study of pregravid physical activity and sedentary behaviors in relation to the risk for gestational diabetes mellitus. Archives of Internal Medicine 2006166 543-548. (doi:10.1001/archinte.166.5.543)

32 Metzger BE, Buchanan TA, Coustan DR, de Leiva A, Dunger DB, Hadden DR, Hod M, Kitzmiller JL, Kjos SL, Oats JN et al. Summary and recommendations of the Fifth International WorkshopConference on Gestational Diabetes Mellitus. Diabetes Care 200730 (Supplement 2) S251-260. (doi:10.2337/dc07-s225)

33 Gradmark A, Pomeroy J, Renstrom F, Steiginga S, Persson M, Wright A, Bluck L, Domellof M, Kahn SE, Mogren I et al. Physical activity, sedentary behaviors, and estimated insulin sensitivity and secretion in pregnant and non-pregnant women. BMC Pregnancy Childbirth 201111 44. (doi:10.1186/1471-2393-11-44)

34 Coughlan MT, Vervaart PP, Permezel M, Georgiou HM \& Rice GE. Altered placental oxidative stress status in gestational diabetes mellitus. Placenta 200425 78-84. (doi:10.1016/S01434004(03)00183-8)

35 Falcao-Pires I, Castro-Chaves P, Miranda-Silva D, Lourenco AP \& LeiteMoreira AF. Physiological, pathological and potential therapeutic roles of adipokines. Drug Discovery Today 201217 880-889. (doi:10.1016/j. drudis.2012.04.007)

36 Golbidi S \& Laher I. Potential mechanisms of exercise in gestational diabetes. Journal of Nutrition and Metabolism 20132013285948. (doi:10.1155/2013/285948)

37 Chasan-Taber L, Fortner RT, Gollenberg A, Buonnaccorsi J, Dole N \& Markenson G. A prospective cohort study of modifiable risk factors for gestational diabetes among Hispanic women: design and baseline characteristics. Journal of Women's Health (Larchmt) 201019 117-124. (doi:10.1089/jwh.2009.1416)

Received 9 November 2015

Revised version received 16 February 2016

Accepted 10 March 2016 